
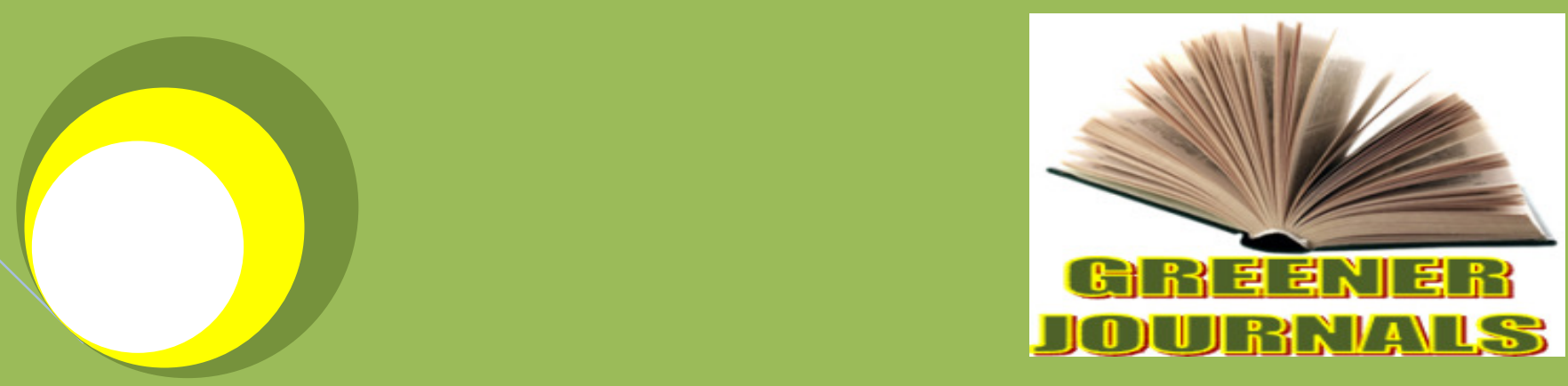

Greeney lournal of Elicucational Research ISSN: 2276-7789 Impact Factor 2012 (UJRI): 0.7230 ICV 2012: 6.05

An Investigation into the Rationale, Clarity of Policies and Timeliness of the Inclusion of the Early Childhood Development (ECD) Programmes in Gweru Urban and Peri-Urban Primary Schools in Zimbabwe

By

Tendai Chikutuma Tichaona Mapolisa 


\title{
An Investigation into the Rationale, Clarity of Policies and Timeliness of the Inclusion of the Early Childhood Development (ECD) Programmes in Gweru Urban and Peri-Urban Primary Schools in Zimbabwe
} ${ }^{1}$ Tendai Chikutuma and ${ }^{2}$ Tichaona Mapolisa

\author{
'Belvedere Technical Teachers' College P.O.Box BE 100 Harare, Zimbabwe. \\ ${ }^{2}$ Zimbabwe Open University P.O.Box MP1119 Mount Pleasant Harare, Zimbabwe. \\ Corresponding Author's Email: tchikutuma@gmail.com/tichmap@gmail.com
}

\begin{abstract}
The paper discusses the experiences of the authors of the research conducted in Gweru urban and peri-urban primary schools. The objective was to investigate the rationale, clarity of policy and timeliness of inclusion of the four to five year olds in the formal schools. The study was conducted in five Gweru urban and peri-urban primary schools. Five school heads, 10 parents and 20 Early Childhood Development (ECD) teachers were purposely sampled. Data were collected using interviews, observations and checklists of the appropriateness of the outdoor and indoor play equipment. Findings showed that there is indeed need to include this age group in the public schools because this makes education accessible to all. The inclusion of four to five year olds in primary schools was not timely because the learners were learning and habituating in unsatisfactory infrastructure and generally the schools were unprepared for them in terms of personnel and play equipment. Since the study justified the need for ECD in the schools, it is however, recommended that a more appropriate environment be sought. It also recommended the need to staff develop ECD teachers and supervisors so that they would become craft literate and craft competent, enough to enable them effectively interpret, implement, monitor and evaluate ECD programmes and policies.
\end{abstract}

Keywords: Policies, Timeliness, Early Childhood Development (ECD), Early Childhood Development (ECD) programmes.

\section{BACKGROUND TO THE STUDY}

There is increased documentation in the need for a curriculum that leads to the development of the zero to six year olds. Writing about ECD, Evans (2002) states that learning begins at birth. Systematic development of learning tools and concepts requires that due attention be paid to the initial education and care of young children. This implies that, parents and communities must be innovative in ensuring that the basic needs of education for all is met at a tender age. In Zimbabwe for example, the commission of inquiry was set up by the president to evaluate the trend of education and care for the zero to six year olds (Nziramasanga, 1999). The commission highlighted the philosophy of education is inculcating values and emphasizing on diversity of cultures, hard work, respectability, adaptability and self-reliance. It was also further recommended that, the ECD programmes be accessible to all in contrast to the prior trend that only the rich could send their four to five years old children to privately owned nursery and preschools.

Taking up the Nziramasanga recommendations the Ministry of Education, Sport, Arts and Culture issued circular minute 14 of 2004, directing all primary schools to increase the zero to six year olds' access to ECD care and education by attaching ECD A (3-4 year olds) and B (4 to 5 year olds) classes in public primary schools. The five to six year olds were meant to be engaged in pre-formal education which in turn was meant to facilitate smooth transition into formal schools. Furthermore, an education director minute number 12 of 2005 stated guidelines on how to implement the inclusion of 3 to 6 year olds in primary schools. In view of all this background, the researchers studied the rationale, clarity of policies and timeliness of the inclusion of three to six year olds in the Gweru urban and peri-urban primary schools.

Informal meetings with school heads revealed that they felt inadequate to run the ECD programmes even though they had the circulars because they did not have the guidelines on how to run the programmes. This maybe 
because the policies, laws and guiding documents lacked interpretation by specialists who could have helped them understand and get the practicalities of the programme. This concurs with Pence (2004) who suggests that in subSahara, policies of running ECD programmes, exist but there is no co-ordination between what is on the ground and what is on paper. This therefore, inspired the researchers to want to know more about the policies running ECD programmes. In view of all the issues highlighted, the researchers studied the rationale, clarity of policies and timeliness of the inclusion of the 3 to 6 year olds in the Gweru urban and peri-urban primary schools.

\section{Statement of the Problem}

The researchers investigated the following question:

- To what extent are the rationale, clarity of policies and timeliness of the inclusion of the 3 to 6 years olds obtaining in the Gweru urban and peri-urban primary schools?

\section{The Historical Development of the term Early Childhood Development (ECD)}

It is interesting to note that, the term ECD has gone through different stages of terminology change. What is notable is that the terms like preschool, nursery school, pre-primary and Early Childhood Education and Care all refer to the zero to six year olds. In Zimbabwe the term ECD was used to describe organised activities of the zero to six year olds. Morrison (1995) justifies the shift from preschool and nursery school to ECD. He states that the terms preschool and nursery school create images of formal school and referred to educational attitudes and values of adults. In support, Ministry of Community Development and Women's Affairs (MCDWA, 1996:7) suggests that, "the term preschool is limited, narrow and tended to see the ECD programme as preparing for formal school". The term ECD is thus comprehensive and refers to all aspects of growth, development and care.

\section{Rationale for ECD Inclusion in Primary Schools}

Traditionally, the majority of nursery schools in the United States of America were operated by private agencies either self -sponsored from the children's fees or sponsored by the state in support of the poor. Evans (2004) highlights later academic success of these children and the variation of sources of funds in the running of the pre-schools. Critics of inclusion suggest that it might be disadvantageous to children's emotional development if they spend too much time at the learning centre and less with their parents (Currie, 2001). According to Morrison (1995), professional parents lobby for inclusion of ECD education and care programmes in public schools because they cannot find affordable quality education and care for their children and thus believe that the schools hold a solution to their problem.

It is also important to include 3 to 6 year olds in the primary schools as the fees charged are reasonable and affordable. For instance the parents interviewed by the Nziramasanga Commission (1999) of Zimbabwe said that private nursery school fees were so exorbitant that inclusion in the primary schools would make education accessible to all. Furthermore, 5-6 year olds (ECD B) also gain creative experiences outside the home. This is possible because schools are capable of providing a rich curriculum that produces an all round competent child. In this view (Nziramasanga, 1999) recommends a curriculum that highlights the 'unhu' or 'ubuntu' philosophy that produces the whole child who is acceptable to society.

However, critics of inclusion of 3 to 6 year olds in public schools cite problems of public schools failing to provide education for the formal groups (Morrison, 1995). For instance, currently, Zimbabwean schools are experiencing shortages of resources like, water, electricity, personnel and stationery. In addition, Zimbabwean public schools lack personnel with specialised skills for this age group as highlighted by UNICEF (2005)'s evaluation on the availability of specialised ECD personnel.

\section{METHODOLOGY}

The researchers in this study used the descriptive survey methodology. This methodology required that the researchers choose the instruments of data gathering and analysis which are interviews and questionnaires (Chiromo, 2006). Five school heads, 10 parents and 20 Early Childhood Development (ECD) teachers were purposely sampled. Purposive sampling enables researchers to choose respondents who possess characteristics desired by a given study (Cohen, Manion and Morrison, 2002). The researchers also used observations and 
checklists to assess the appropriateness of the outdoor and indoor play equipment. Such triangulation of instruments ensures that researchers gather valid and reliable data since the instruments have the capacity to cover for each other's shortcomings (Patton, 2002).

\section{Questionnaires}

Patton (2002) suggests that, the questionnaires are the least expensive. This implies that more can be collected at the same time and venue hence saving time. With regard to this study, questionnaires were used to collect data from school heads, teachers and parents of the five schools in a short space of time. Chiromo (2006) also says that questionnaires give people a feeling of anonymity and thus encourage open ended responses to sensitive issues. The researchers were able to check for completion of items on the spot.

\section{Interviews}

This data collecting instrument involved using open-ended items; implying that several answers were possible (Cohen, Manion and Morrison, 2002). The interview procedure brought detailed data especially about internal mental states or beliefs of the respondents. This was applied especially with rationale to inclusion of 3 to six year olds in the primary schools. The greatest advantage of the interview was its face to face interaction between the researchers and respondents (Patton, 2002). In this case the researchers could decipher a lot of meaning from bodily expressions which revealed hidden convictions. It also accorded the researchers the opportunity to verify given information by seeking further clarification.

\section{Observations and Checklists}

Researchers observed the extent to which the rationale, clarity of policies and timeliness of the inclusion of the 3 to 6 year olds obtaining in the Gweru urban and peri-urban primary schools. Observations and checklists enable the researchers to collect first hand information (Chiromo, 2006). "We recorded what we felt was of interest to the present study on the checklists".

\section{Data Interpretation and Analysis}

The analysis of data took the form of identifying and grouping from all data collection instruments into relevant issues of concern. It was through this identification and fitting of data into respective categories that the researchers took note of important messages of the study. The analysis entailed descriptions of findings from research instruments of the rationale, timeliness and clarity of policy of ECD inclusion in the primary schools. At the point of the interpretation, the thrust was to make sense of data. Interpretation involved an examination of data collected through the instruments against the background of the Government policy of ECD inclusion in primary schools and the literature reviewed in preparation for this research.

\section{Findings}

What came out of the study is that it was necessary to include 3 to 6 year olds in the primary schools. The reasons being that prior to Government policy of ECD inclusion in the public schools, pre-school and nursery was mainly for the elite who could be sent by their rich parents. Some of the reasons given by the school heads were that ECD

Inclusion into primary schools facilitated smooth transition to grade one. At Mugwavha school which was under study, the teacher in charge said "we no longer need to take our children through the six weeks period of preformal learning since this is done at ECD A and B level and thus we manage to save time". The Head of school Muti had this to say, "the learners already know the ethos, rules and regulations of the school such that the learners in grade one find it easy to fit in the school system". To quote yet another head of White school, "the learners would have made friends in the previous year and this gives them security in the new year". From these views, it is clear that it is justifiable to include 3 to 6 year olds in the primary schools. Interviewed parents also echoed strongly their appreciation of the inclusion of ECD A and B learners in the primary schools. One parent is quoted saying, "I am able to buy my child's uniform in advance because I am assured of his vacancy at this school and am also able to save his fees for the next year knowing the exact figures". 
With regards to the timeliness of the implementation of the ECD policy of inclusion into the primary schools, the school heads felt that they were driven to respond to the policy of inclusion without the proper facilities for the age level of 3 to 6 year olds. The school head of Mugwavha in response to the interview question is quoted saying, "this inclusion was not well planned and all it has done is creating problems in terms of having to come up with classrooms, appropriate play facilities, looking for qualified personnel and appropriate bathroom facilities". The

White school head who did not respond promptly to the policy wanting to vet the teachers was cautioned strongly by her bosses. The school head's words are quoted as, "I wanted to make sure I employ a properly qualified teacher and also to get staff developed myself so that I could run the ECD programme efficiently and professionally and yet I got a strong warning to respond to the policy". The other four school heads admitted that, though they had implemented the policy of inclusion in the primary schools, they felt inadequate to supervise the teachers, parents and ECD learners since it required specialisation. They all said that they would have needed some training so as staff development to be able to run this programme. Muti school head is quoted saying, "so far this ECD programme has been trial and error and I do not know what I am supposed to be doing".

To the question, did you get instruments that guide you on how to implement and run the ECD programme within the primary schools? We got a response from the school head saying that, they got an announcement at a school heads meeting to including the 3-6 year olds in primary schools. Later on they received circular number 12 of 2004 informing all schools to increase access of ECD education and care to the 3 to 6 year olds long after the verbal announcement. Although the school heads received this policy circular, they said that, it was not clear on how the ECD programme was to be implemented and run though the day of commencement was given.

Later on the school heads said that they got circular minute 12 of 2005 which gave guidelines on how to implement ECD A and B as regulated by the Education Act of 1996 and as amended by statutory Instrument 106 of 2005. This circular according to school heads seemed to offer more guidance on how to implement and run ECD programmes. However, the school heads noted that even though they had the circulars, they still found it difficult to implement the policy because they lacked the practical steps of how to do it.

\section{Analysis and Discussion of Findings}

What emerged was that generally parents were happy with the inclusion of ECD $A$ and $B$ learners in the primaryschools. Administrators and teachers also appreciated the inclusion of ECD A and B learners in the primary schools.

However, administrators admitted incompetence in handling this group of learners. While it is justified that inclusion of 3 to 6 year olds in primary schools is important, critics' arguments have been proved right in that timing of the implementation of the inclusion policy was not right because the personnel and facilities were not meeting the required standards locally and internationally. According to these views, the inclusion would have needed more time for preparation but the school heads had to respond immediately to the circulars. Views expressed by the school heads showed that the inclusion was not timely. One reason why the school heads felt incompetent was maybe because they were not trained and staff developed on professional expectations peculiar to the group in question. This point is echoed by Evans (2002) who says while the ECD inclusion policy is an acceptable principle and practice of effectively socialising and enhancing academic performance of the 3 to 6 year olds, developing countries like Zimbabwe are perhaps not ready to facilitate its full implementation. This may be because there were was no need for assessment in terms of resources required and the general preparation necessary for the running of ECD $A$ and $B$ classes. Therefore, the inclusion of ECD A and B was not timely.

The rush to enforce the implementation of ECD A and B programme in primary schools was perhaps because, they felt they were behind in responding to the millennium goals of which one of them was education for all including the zero to six year olds. UNESCO (2005) reporting on the world summit on the millennium goals underscores that Zimbabwe being a participant of the conferences and having signed the protocols agreed to make education accessible to all. The inclusion policy may also have been in response to the Nziramasanga (1999) recommendations which highlighted that pre-school and nursery must be accessible to all.

Findings show that the inclusion policy was a noble idea but was not clear in terms of administrators' knowledge of how to run and who to engage as teachers. This may be because the policies lacked interpretation by the specialists in policy implementation. This concurs with Pence (2004) who states that ECD implementation in SubSaharan Africa is scarce and that while the policies exist, often such laws and policies are sectoral in nature, lack coordination and are not adhered to. 


\section{CONCLUSION}

The inclusion of 3 to 6 year olds in primary schools in Zimbabwe is justified as proved by all research instruments administered to parents, teachers and administrators. It can therefore be concluded that the inclusion of ECD A and B children in the primary schools is of great value to the learners, the school and the community. The study also revealed that the implementation and running of ECD A and B in primary schools was trial and error and administrators and ECD teachers lacked specialisation. It can therefore be concluded that the inclusion was not timely. It can be concluded that the school administrators should be staff developed by ECD specialists so as to improve the current administration and those who are yet to implement the policy of including 3 to 6 year olds in the primary schools.

The study clearly shows that policies that existed were unclear as to the implementation and running of ECD programmes.

\section{RECOMMENDATIONS}

In view of the findings and conclusions, the researchers recommend the:

- $\quad$ need for involving all interested stakeholders in the training of ECD teachers and supervisors so that ECD programmes would not be run through trial and error,

- $\quad$ the need to staff develop ECD teachers and supervisors so that ECD teachers and supervisors would become craft literate and craft competent enough, to enable them to effectively interpret, implement, monitor and evaluate ECD programme policies, and

- $\quad$ need to carry out a nationwide study in the same area for the purposes of building a more academically sound knowledge base.

\section{REFERENCES}

Cohen, L., Manion, L. \& Morrison, K. (2002). Research Methods in Education. London and New York. Routledge Falmer.

Chiromo, A.S. (2006). Research Methods and Statistics in Education. A Student's Guide. Gweru. Beta Print.

Currie, J. (2001). "Early Childhood Programmes", The Journal of Economic Perspectives 15 (2): 213-218.

Evans, J.J. (2002). Creating a shared vision. How Policy affects Early Childhood care and Development. Coordinator's Note Book CD -ROM. Te Consultative group on Early Childhood Care and Development. Washington D.C. World Bank, 1995.

Morrison, G.S. (1995). Early Childhood Education Today. Englewood Cliffs. New Jersey: Prentice Hall. Ministry of Community Development and Women's Affairs [(MCDWA, 1996] Curriculum Handbook for the National Early Childhood Education and Care Programme. Harare: Ministry of Education.

Patton, M. Q. (2002). Qualitative Evaluation Methods. Beverly Hills: Sage Publishers.

Pence, A (2004). Early Childhood Policy Implementation in Africa. UNESCO. Early Childhood Family Policy series. No. 9. November 2004. Columbia: University of Victoria.

Nziramasanga,C. (1999). The Nziramasanga commission in the inquiry of Education: Harare: Government Printers. UNESCO, (2005). Implementation Guidelines for the UNESCO/OECD Early Childhood Policy Project Review. 